\title{
NARRACIÓN Y ARGUMENTACIÓN EN LAS "CRÓNICAS DE INDIAS" SOBRE EL DIARIO DE COLÓN, ENTRADA DEL 12 DE OCTUBRE DE 1492
}

El año 1492 constituye en la historiografía española un dato doblemente simbólico: por una parte, se hace coincidir con esta fecha el fin de un largo proceso de unificación nacional; por otra, el comienzo de la expansión territorial de España a escala mundial. La unificación nacional se considera alcanzada tras la conquista por las armas del último reducto musulmán en tierras ibéricas (reino árabe de Granada) y expulsión (decretada) de los judíos. La expansión territorial -que habría de llevar en 1493 a la anexión de los condados de Rosellón y Cerdaña, a la ocupación del reino de Nápoles en 1503, a las conquistas de Melilla (1497) y Orán (1509) y a otras incursiones en África, como más tarde habría de llevar a las guerras de religión en Europa (con el sometimiento de los Países Bajos) - comienza con la toma de posesión de las "Indias occidentales" por parte de Cristóbal Colón, en nombre de los reyes de Castilla y Aragón, el día 12 de octubre de 1492.

En este mismo año se imprime en Salamanca la primera gramática de la lengua castellana. Su autor, Nebrija, la dedica a la reina Isabel con palabras que muestran una conciencia nacional y una temprana interpretación, en los términos señalados, del pasado y del porvenir de España - al que la lengua, "compañera del Imperio", debía servir. En efecto, Nebrija señala en su dedicatoria cómo "los miembros \& pedaços de España, que estauan por muchas partes derramados, se reduxeron \& aiuntaron en un cuerpo \& unidad de reino". Este proceso, que coincide para $\mathrm{Ne}$ brija con la formación y crecimiento de la lengua castellana "hasta la monarchía \& paz de que gozamos", es obra de "la bondad \& providencia divina" ante todo. Pero lo es también de "la industria, trabajo \& diligencia' de la Corona. Nebrija concluye: 
Assí que, después de repurgada la cristiana religión, por la cual somos amigos de Dios, o reconciliados con él; después de los enemigos de nuestra fe vencidos por guerra \& fmerça de armas, de donde los nuestros recebían tantos daños \& temían mucho maiores; después de la justicia \& essecución de las leies que nos aiuntan \& hazen bivir igualmente en esta gran compañía que llamamos reino \& república de Castilla; no queda ia otra cosa sino que florezcan las artes de la paz. Entre las primeras, es aquélla que nos enseña la lengua ${ }^{1}$.

Aunque focalizando ante todo la techné política de Fernando de Aragón en su uso de lo religioso, hasta convertir al rey español en un "quasi principe nuovo", Maquiavelo interpreta en Il Principe el "fondamento" del Estado español y sus primeras "gestas", de manera semejante a la de Nebrija:

Nessuna cosa fa tanto stimare uno principe, quanto fanno le grandi imprese e dari di sé rari esempli. Noi abbiamo ne' nostri tempi Ferrando di Aragona, presente re di Spagna. Costui si può chiamare quasi principe nuovo perché di uno re debole è diventato per fama e per gloria el primo re de' Cristiani; e, se considerrete le azioni sua, le troverrete tutte grandissime, e qualcuna estraordinaria. Lui, nel principio del suo regno, assaltò la Granata: e quella impresa fu il fondamento dello stato suo [ . . . $]$ Oltre a questo, per potere intraprendere maggiori imprese, servendosi sempre della religione, si volse a una pietosa crudeltà, cacciando e spogliando el suo regno de' $\mathrm{Ma}$ rrani: né può essere questo esemplo più miserabile né più raro. Assaltò sotto questo medesimo mantello l'Affrica: fece l'impresa di Italia: ha ultimamente assaltato la Francia; e così sempre a fatte e ordite cose grandi, le quali sempre hanno tenuto sospesi e ammirati gli animi de' sudditi e occupati nello evento di esse. E sono nate queste sua azioni m modo l'una dall'altra, che non ha dato mai, infra l'una e l'altra, spazio agli uomini di potere quietamente operarli contro².

Para comprender esta convergencia de lo lingüístico, religioso y político en la fecha simbólica de 1492 (fecha de la consolidación del Estado-nación, pero también de los comienzos de la expan-

1 Antonio de Nebrija, "Dedicatoria", Grammatica Castellana. Cito según facsímil de la ed. de 1492, publicado por R. C. Alston, The Scholar Press, Menston, 1969.

${ }^{2}$ Nicollo Machiavella, Il Principe, ed. de Ettore Janni, Biblioteca Universale Rizzoli, Milano, 1950, cap. XXI: "Che si conviene a un principe perché sia stimato", pp. 90-91. 
sión imperial de España) tendremos que remontarnos al momento en que nace España en cuanto Estado moderno, e incluso a su proceso de gestación como Estado-nación allá por los últimos siglos del período llamado "Reconquista". Sólo así prodremos comprender igualmente el impulso dinámico que lanza al joven Estado español a la aventura de América como empresa histórica, realizada bajo el signo (ideológico) de una misión religiosa que le es encomendada por el Papa en cuanto "Vicario de Cristo [de Dios] en la tierra". Greo poder fijar como fecha de nacimiento del Estado español, y de la nación española, el día 18 de octubre de 1469 (otra fecha altamente simbólica, pero mucho menos explotada en la historiografía española). Su lugar, Valladolid. Pues fue allí donde se unificaron, en dicha fecha, los dos grandes reinos cristianos de Castilla y Aragón, al unirse en matrimonio los sucesores de ambas coronas: Isabel I de Castilla y Fernando V de Aragón. Nos encontramos en las postrimerías de la Edad Media, época en que van surgiendo ciertos bloques nacionales europeos al ritmo en que sus monarquías se emancipan del Pontífice de Roma y del Emperador de la Cristiandad ${ }^{3}$. Pero el Estado-nación español, aunque dentro de este mismo marco histórico, nace (ideológicamente) bajo el signo contrario. De ahí que tengamos que detenernos aún a analizar el acto fundacional, el casamiento concertado entre Isabel de Castilla y Fernando de Aragón, lo mismo que la lucha que se sigue inmediatamente después contra el reino árabe de Granada, para comprender mejor la misión y el significado que se atribuye a sí mismo el nuevo Estado.

Comencemos pues por fijar nuestra atención, siquiera brevemente, en ese pasado inmediatamente anterior al momento en que se constituye y consolida el Estado español, indagando la dinámica a que responde tal casamiento, que será la misma que va a lanzar al nuevo Estado a un proyecto (futuro), concebido como misión histórica.

Tras el establecimiento de los árabes en tierras ibéricas, se pro-

${ }^{3}$ En L'Idée de Nation (P.U.F., Paris, 1969) Jean-Jacques Chevallier ha resumido así este proceso: "En dépit des survivances de Cités-États, aux dimensions petites mais à la puissance commerciale et politique appréciable, en dépit des vélléités ou des réalisations éphémères d'Empires démesurés, on voit émerger irrésistiblement, de la fin du Moyen Age au début des Temps modernes (Renaissance et Reforme), les grands États-Nations de forme monarchique: France, Angleterre, Espagne. La notion de souverainité, doctrinée par Jehan Bodin, deviendra leur robuste armature juridico-politique. Souverainité du roi, en Parlement ou non, et souverainité de l'État tendront à l'État tendront à l'identification"' (p. 50). 
duce una fragmentación de las mismas en pequeños reinos, unos cristianos, otros musulmanes. Estos reinos, que viven en continuas luchas de expansión territorial, establecen sus alianzas según la conveniencia estratégica del momento más que según el credo religioso. En Toledo asistimos incluso a un gigante esfuerzo cultural en que colaboran estrechamente las tres grandes religiones que conviven durante la Edad Media en la Península Ibérica: judaísmo, cristianismo e islam. Pero en los comienzos del siglo xill empieza a desarrollarse en los reinos cristianos de la $\mathrm{Pe}$ nínsula Ibérica la conciencia (ideológica) de una misión conjunta (de carácter religioso) a cumplir: la expulsión de los musulmanes de las tierras ibéricas, en una especie de "cruzada cristiana' contra " el infiel"'. Es el papa Inocencio III quien lanza esta idea al declarar "causa cristiana" la guerra que Alfonso VIII preparaba contra los árabes, concediendo "bula de cruzada" al rey castellano. Los reinos de Navarra, León y Aragón, como otros reinos de la Europa cristiana, envían sus tropas en ar uda del rey de Castilla, uniéndose así en un esfuerzo común que los lleva a la victoria de Las Navas de Tolosa (1212). Tras el rico botín obtenido, la idea cada vez más presente de una "guerra santa" impulsará toda una serie de alianzas militares y matrimonios que contribuye a la progresiva unificación y expansión de los reinos cristianos de la Península Ibérica. De este modo, aquella multitud de reinos cristianos (Galicia, Asturias, León, Navarra, Castilla, Aragón, Cataluña, Portugal) se reduce hasta formar sólo dos Estados cristianos que dominarán la Península Ibérica en su totalidad: de un lado, Portugal; del otro, Castilla y Aragón, cuya unión permite la victoria sobre Granada. Tal unión y tal victoria marcan así el fin del largo proceso histórico que pone en marcha Inocencio III al declarar la reconquista castellana "causa cristiana" y "cruzada" contra "el infiel"'

La idea de la Reconquista es por tanto el elemento coadunador de los diversos reinos cristianos de la Península Ibérica, en una dinámica que conduce a la unión de Castilla (que había fu-

${ }^{4}$ En su Historia de la bula de la cruzada en España (Vitoria, 1958) José GoÑI Gaztambide hace sinónimos en la Edad Media española los términos "Reconquista" y "Cruzada", con lo que generaliza, según uso tradicional, la "lucha contra el infiel" a los ocho siglos de presencia árabe en la Península Ibérica. Al intentar documentar el uso de la palabra "cruzada" se contenta, sin embargo, con afirmar que "aparece ya en la primera mitad del siglo xiII" (p. 151), con lo que creo que más bien confirma mi tesis del lanzamiento de esta idea por Inocencio III en los comienzos del siglo xill. 
sionado bajo su corona los viejos reinos de Galicia, Asturias, León y Castilla) y Aragón (que había aunado, por su parte, los viejos reinos de Navarra, Aragón y Cataluña). La idea de la Reconquista genera igualmente el ideal político y religioso que convierte en "caudillos" de la "cruzada contra el infiel" a aquellos reyes que antes se titularan "emperadores" por abrigar bajo sus coronas a cristianos, judíos y musulmanes. Su ideal pasa a ser entonces la "pureza de la fe" en sus territorios, y sus esfuerzos de expansión territorial se confunden (ideológicamente) con la expansión de la cristiandad, precisamente en los momentos en que la cristiandad europea asistía a su ocaso.

Si en los primeros siglos del período que la historiografía española designa, generalizando, con el nombre de "Reconquista" conviven en cada reino afincado en tierras ibéricas cristianos, judíos y musulmanes -y se erigen templos para los tres cultos-, a medida que se va consolidando la idea de la "cruzada contra el infiel" no va quedando, lo mismo para el musulmán que para el judío nacido o establecido en "territorio cristiano", otra alternativa que la conversión o la huida. En tales circunstancias, se multiplican las "falsas conversiones". Contra ellas crean los Reyes Católicos, en 1478, los tribunales de la "Santa Inquisición", encargándoles la difícil tarea de velar por "la unidad religiosa y social" del nuevo Estado. Nos encontramos aquí pues frente a una institución político-religiosa, exponente de la política interior de unos reyes que se consideran los garantes de la "pureza de la fe" de sus súbditos. Libres en sus territorios de los "enemigos interiores de la fe", bajo la garantía de tales tribunales, no es de extrañar que se lancen después a la expansión de la misma, cumpliendo así a la letra la "misión religiosa" que les había sido encomendada por el "Vicario de Cristo en la Tierra", el Papa. Buena prueba del interés puesto por Roma en la eliminación total de la presencia islámica en territorio hispano es la serie de bulas de cruzada que precede a la conquista de Granada, alentando la preparación de la misma. Ya el 13 de noviembre de 1479 (diez años después de la unión de Castilla y Aragón) promulga el papa Sixto IV la primera bula, gesto que se repite - con la concesión de nuevos privilegios y nuevas indulgencias- en 1482, en 1485, en 1487, en 1489 y en 1491 . Dicen los cronistas que, cuando se supo en Roma la capitulación del reino árabe de Granada ante los Reyes Católicos, se echaron al vuelo las campanas y se celebró el "triunfo cristiano" con fiestas religiosas y profanas.

Tras haber seguido la génesis de la "nación" española y su 
organización como "Estado" en sentido moderno, estamos en mejores condiciones - espero- de comprender ese proyecto que se va a proponer cumplir la joven nación formada bajo el signo de la "lucha religiosa", de la "cruzada contra el infiel" establecido en sus propios territorios, y más allá incluso del logro de la unificación territorial-religiosa de fronteras adentro. Parece como si el homo hispanus se hubiese identificado de tal manera con el ideal caballeresco de la cruzada, que, tras conseguir la "pureza de la fe" interior, se lanza a imponerla en el mundo todo ${ }^{5}$. En efecto, inmediatamente después de la conquista de Granada, se organiza una serie de expediciones al norte de África, donde entre 1497 y 1512 conquistan los españoles diversas plazas y fortificaciones (Melilla, Alcazaquivir, Orán, Trípoli, etc.). Se establecen así bases militares para las flotas españolas, que sirven lo mismo a la defensa de las posesiones españolas en el sur de Italia que a la expansión de las mismas, garantizando el dominio español del Mediterráneo ("Mare nostrum"). Sirve como pretexto el "peligro turco", que amenaza a "la Cristiandad". Y al aparecer la Reforma protestante, lucha Carlos V contra ella con el mismo celo con que sus antecesores lo habían hecho contra la Media Luna en España y fuera de España. La misma política continuará Felipe II, quien arruina la economía española en las guerras de religión en Europa y en la expedición contra los turcos — que vence, en 1571, en Lepanto. La lucha de los tercios españoles en los Países Bajos y la "armada invencible" enviada contra Inglaterra son empresas militares llevadas a cabo igualmente bajo el signo de una (frustrada) expansión político-religiosa de la "gran potencia católica" que los Austrias quisieron oponer a la Reforma protestante.

Pero será en la conquista y colonización de América donde se pondrá de manifiesto de manera más evidente la identificación (ideológica) de la política expansionista española con los ideales de expansión evangelizadora de la Iglesia católica. Poco más de seis meses después de haber puesto pie Colón en el "Nuevo Mundo" se otorga a los españoles, por la bula Inter coetera del papa (español) Alejandro VI, el encargo de "misionar" los territorios "descubiertos" por Colón. Se trataba de una especie de missio canoni$c a$, por la que se enviaba a los reyes españoles a predicar el evangelio y convertir a la fe católica a los "indios", nombre que designa aún a los aborígenes del continente americano en testimonio mul-

5 Así lo explica Marcei. Bataillon en su obra monumental Erasme et l'Espagne, Droz, Paris, 1937. Ver esp. pp. 55-65. 
tisecular del error colombino. Cuán al pie de la letra asumieron los Reyes Católicos esta misión religiosa que Roma les encomendara en América, queda bien patente en el título con que designaban su papel en esta nueva causa cristiana: "Regio Vicariato Apostólico", título puramente religioso por el que los reyes asumen una misión de indole religiosa en cuanto "vicarios" delegados por la Sede Apostólica, por Roma. Y cuán al pie de la letra dieron cumplimiento los reyes españoles a esta misión que Roma les encomendara, queda de manifiesto en el desarrollo alcanzado por la Iglesia en el Nuevo Mundo, ya a principios del siglo XvII. En poco más de un siglo de labor misionera se habían erigido cinco sedes metropolitanas con 29 obispados sufragáneos: el número de misioneros que acompañaran a conquistadores, colonos, aventureros y buscadores de oro en las nuevas tierras ascendía a varios millares, y el número de iglesias, conventos y catedrales que se había levantado era muy considerable ${ }^{6}$.

No insistiré aquí en la (conocida) serie de abusos cometidos en el cumplimiento de esta misión religiosa. Más nos interesa la división de opiniones en torno a la misma y al "título de dominio" sobre las "Indias occidentales", que se basa en tal misión.

Así, para el P. Bartolomé de las Casas o para Pedro Mártir de Anglería los indios fueron sometidos a una horrible esclavitud en nombre de Dios y del evangelio. No la ley de Dios, sino la codicia, la envidia y la ira. Éstos son para Bartolomé de las Casas los sentimientos que los españoles llevan al corazón de los indios, quienes, según la descripción del Diario de Colón (que recuerda la que Ovidio hace de la "Edad de Oro"'en sus Metamorfosis), vivían en estado de naturaleza pura. También Pedro Mártir de Anglería (parafraseando expresamente a Ovidio) dice acerca de los indios, en De orbe novo (1530):

Sine legibus, sine libris, sine iudicibus suapte natura rectum colunt $[\ldots]$ sylvestribus fructibus contentos $[\ldots]$ uti legitur de aurea aetate $^{7}$.

${ }^{6}$ Sobre el título de los reyes españoles y su actividad "misionera" en Indias, véase AnTonio Egaña, La teoría del regio vicariato español en Indias, Roma, 1958, y Antonio Rouco Varela, Staat und Kirche im Spanien des 16. Jahrhunderts, Max Hueber Verlag, München, 1965.

${ }^{7} \mathrm{El}$ texto de Colón que comentamos en las páginas que siguen se hace igualmente eco de tales textos al describir la condición de los indios; Tomás Moro localizará en América su "Utopia", que los jesuitas realizarán más tarde en las "reducciones" del Paraguay. El mito guía así primero la lectura de la realidad; después, su propia realización. 
Para otros autores, como por ejemplo, para el cronista de Cortés, Francisco López de Gómara, la colonización de América significa la gesta ("épica") de "la redención de los pueblos más primitivos de la tierra", que hasta entonces habían vivido en "canibalismo, poligamia, politeísmo no libre de cruentos sacrificios humanos". Con citas bíblicas se describe la conquista de América como "la liberación de los indios de la esclavitud de Egipto", y se iguala a la "conquista de la vid del Señor" y a la "toma de posesión de la tierra prometida" por parte del "pueblo elegido de Dios'. En su Suma de Geografia (1519), Martín Fernández Enciso llega a servirse del texto bíblico de la conquista de Jericó, que calca literalmente en una de sus descripciones de la estrategia militar de los conquistadores, subrayando así esa elección divina del pueblo español:

E después envió Josué a requerir a los de la primera ciudad, que era Jericó, que le dejasen e diesen aquella tierra, pues era suya porque se la había dado $\operatorname{Dios}^{8}$.

Efectivamente, antes de afrontarlos en batalla, se leía a los indios un "requerimiento", auténtico tratado teológico en que se evocaba la historia de la salud del hombre, desde la creación del mundo y el primer pecado hasta su redención por Cristo y la fundación de una Iglesia, depositaria de tal redención y de la autoridad del mismo Cristo. Es el Papa, vicario de Cristo y jefe de la Iglesia, quien ha encomendado a los reyes de Castilla aquellas tierras. En su nombre y potestad se exigía, en consecuencia, la aceptación del bautismo por parte de sus pobladores y el acatamiento de la autoridad de los españoles sobre ellos. Es conocida la respuesta que - se dice- recibieron los misioneros y conquistadores de aquel pueblo de la región de Sinú, en la actual Colombia, tras haber oído el "requerimiento" a reconocer la autoridad sobre ellos que el Papa había concedido a los reyes de Castilla, y a aceptar el bautismo cristiano:

Estaban de acuerdo aquellos indios en que no había sino un Dios; pero en lo que decía que el Papa era señor del Universo y que él había fecho merced de aquellas tierras a los reyes de Castilla, dixeron que el Papa debiera estar borracho cuando lo fizo, pues daba

${ }^{8}$ Gf. Francisco López de Gómara, Historia general de las Indias, Atlas, Madrid, 1946, t. 22 de la BAE: Historiadores primitivos de Indias, I; MARTín FERNÁndez Enciso, Suma de Geografía, Sevilla, 1519. 
lo que no era suyo. Y que el rey que pedía y que tomaba tal merced debía ser algún loco, pues pedía lo que era de otros ${ }^{9}$.

Esta visión controvertida de la conquista, como la controversia que los textos del P. Bartolomé de las Casas provocan en la Universidad de Salamanca en torno a los 'títulos de dominio', que legitiman la presencia de los españoles en Indias, y la que el mismo P. Las Casas sostiene contra el P. Sepúlveda en torno a la "naturaleza del indio", muestra unas convicciones compartidas: la existencia de una "misión religiosa" en Indias, bien o mal cumplida por parte de los españoles, y una descripción de sus pobladores que insiste en sus diferencias respecto al (modelo) español (para bien, idealizándolos; o para mal, condenando su "barbarie"). Sus posturas no difieren por tanto ni en lo gnoseológico ni en lo axiológico. Sólo difieren en la selección de los hechos narrados de acuerdo con una argumentación interpretativa de una conquista cuya legitimidad nadie pone en duda, ni siquiera quienes insisten en destacar sus efectos funestos. Un análisis de este corpus textual que se limite al estudio de sus contenidos narrativos no puede por ello aportar otra cosa que una toma de posición polémica a partir de la visión dualista, maniquea, que ha dominado durante siglos la historiografía en torno a la presencia española en América ${ }^{10}$. En lo que sigue intentaré, a partir del análisis discursivo, poner de relieve el cambio de mentalidad que se está operando en la España que produce y consume estos textos. Para ello tendremos que prestar más atención a la organización del relato que a lo narrado en sí. Sólo así podremos ir, más allá del análisis de las informaciones (explícitas), a los presupuestos (implícitos) que el texto oculta más o menos intencionadamente. Se trata en último término, por tanto, de buscar ese subconsciente (colectivo) reprimido por la instancia (ideológica) de un Superyo que convierte en "nacionales" las aspiraciones e intereses de los grupos hegemónicos de aquella España imperial - y que, por la inercia que caracteriza a las ideologías, perduran como tales aún en nuestros días.

${ }^{9}$ En su Historia general y natural de las Indias, libro 29, cap. VII, Gonzalo FERnÁNDEZ DE Oviedo transcribe y comenta el texto del "Requerimiento" (vol. 3, pp. 227 ss. en la ed.. de Pérez de Tudela, 5 vols., Atlas, Madrid, 1959, ts. 117-121 de la BAE). Para la (poco verosímil) anécdota, cf. Mariano PlCón Salas, De la Conquista a la Independencia, F.C.E., México, 1969, p. 44.

10 Todavía en nuestros días domina esta visión polémica a la que ni siquiera Todorov pudo escapar en su libro La Conquête de l'Amérique. La question de l'autre, Éds. du Seuil, Paris, 1982. 
Analicemos, como ejemplo, la primera visión del indio, tal como la describiera Colón en su Diario de viaje. Este texto, cuyo original no se ha conservado, nos ha sido trasmitido en copia-resumen del P. Bartolomé de las Casas ${ }^{11}$. La Historia del Almirante, biografía de su padre escrita por Hernando Colón, se hace eco del mismo, al igual que las Instrucciones que Colón recibe de los Reyes en 1493 para su segundo viaje, y el propio Colón en su correspondencia ${ }^{12}$. La entrada del jueves, 11 de octubre de 1492, en que se relatan también los acontecimientos del día 12 de octubre sin transición alguna, termina así:

Esto que sigue son palabras formales del Almirante, en su libro de su primera navegación y descubrimiento de estas Indias. "Yo, dice él, porque nos tuviesen mucha amistad, porque conoscí que era gente que mejor se libraría y convertiría a nuestra Santa Fe con amor que no por fuerza, les di a algunos de ellos unos bonetes colorados y unas cuentas de vidrios que se ponían al pescuezo, y otras cosas muchas de poco valor con que hobieron mucho placer, y quedaron tanto nuestros que era maravilla. Los cuales después venían a las barcas de los navíos adonde nos estábamos, nadando, y nos traían papagayos y hilo de algodón en ovillos y azagayas, y otras cosas muchas y nos las trocaban por otras cosas que nos les dábamos, como cuentecillas de vidrio y cascabeles. En fin, todo tomaban y daban de aquello que tenían de buena voluntad. Mas me pareció que era gente muy pobre de todo. Ellos andaban todos desnudos como su madre los parió, y también las mujeres, aunque no vide más de una farto moza y todos los que yo vi eran todos mancebos, que ninguno vide de edad de más de treinta años; muy bien hechos, de muy fermosos cuerpos, y muy buenas caras; los cabellos gruesos cuasi como sedas de cola de caballo, e cortos; los cabellos traen por encima de las cejas, salvo unos pocos detrás que traen largos, que jamás cortan; de-

${ }^{11}$ Cito el Diario de Colón, en la recopilación de Las Casas, por: Colección de los viajes y descubrimientos que hicieron por mar los españoles desde fines del siglo xv, de Fernández de Navarrete (vol. 1, pp. 86 ss. en las Obras de Don Martín Fernández de Navarrete, ed. de Carlos Seco Serrano, Atlas, Madrid, 1954, ts. 75-77 de la $B A E$ ).

12 Cito el texto de Hernando Colón por la ed. de Luis Arranz, Historia 16, Madrid, 1984 (Crónicas de'América, 1); reproducimos el texto de las Instrucciones en el Apéndice del vol. colectivo 1492-1992: RefDiscovering Colonial writing, The University of Minnesota Press, Minneapolis, 1989 (Hispanic Issues, 4); la correspondencia de Colón, en especial la carta a Luis de Santángel del 15 de febrero/14 de marzo de 1493 (en la que encontramos una descripción de los indios en los mismos términos del Diario) puede consultarse en FernánDEZ de NavarReTe, op. cit., pp. 167 ss. en la ed. mencionada en la n. 11. 
llos se pintan de prieto, y ellos son de la color de los canarios, ni negros ni blancos, y dellos se pintan en blanco y dellos de colorado, y dellos de lo que fallan, y dellos se pintan las caras, y dellos todo el cuerpo, y dellos sólo los ojos, y dellos sólo el nariz. Ellos no traen armas ni las cognoscen, porque les amostré espadas y las tomaban por el filo, y se cortaban con ignorancia. No tienen algún fierro; sus azagayas son unas varas sin fierro, y algunas de ellas tienen al cabo un diente de pece, y otras de otras cosas. Ellos todos a una mano son de buena estatura de grandeza, y buenos gestos, bien hechos; yo vide algunos que tenían señales de feridas en sus cuerpos, y les hice señas qué era aquello, y ellos me amostraron cómo allí venían gentes de otras islas que estaban acerca y les querían tomar, y se defendían; y yo creí, e creo, que aquí vienen de tierra firme a tomarlos por captivos. Ellos deben ser buenos servidores y de buen ingenio, que veo que muy presto dicen todo lo que les decía, y creo que ligeramente se harían cristianos, que me pareció que ninguna secta tenían. Yo, placiendo a nuestro Señor, levaré de aquí al tiempo de mi partida seis a V.A. para que desprendan fablar. Ninguna bestia de ninguna manera vide, salvo papagayos en esta isla". Todas son palabras del Almirante ${ }^{13}$.

Antes de la cita en estilo directo que introduce la frase "Estas que siguen son palabras formales del Almirante" y cierra la solemne fórmula "Todas son palabras del Almirante", Las Casas recopila los acontecimientos de ese día en la forma habitual en él (relato en pretérito épico con citas en estilo indirecto):

A las dos horas después de medianoche pareció la tierra [...] Amañaron todas las velas [...] temporizando hasta el día viernes que llegaron a una isleta de los Lucayos, que se llamaba en lengua de indios Guanahaní. Luego vieron gente desnuda, y el Almirante salió a tierra en la barca armada, y Martín Alonso Pinzón y Vicente Anes, su hermano, que era capitán de la Niña. Sacó el Almirante la bandera real [...] Puestos en tierra vieron árboles muy verdes y aguas muchas y frutas de diversas maneras. El Almirante llamó a los dos capitanes y a los demás que saltaron en tierra, y a Rodrigo Descovedo, escribano de toda la armada, y a Rodrigo Sánchez de Segovia, y dijo que le diesen por fe y testimonio cómo él por ante todos tomaba, como de hecho tomó, posesión de la dicha isla por el Rey e por la Reina sus señores [...] Luego se ayuntó allí mucha gente de la isla ${ }^{14}$.

${ }^{13}$ Diario, pp. 95-96.

${ }^{14}$ Ibid. 
En su Historia de las Indias procede Bartolomé de las Casas de idéntica manera en cuanto a la cita directa del Almirante. Al final, añade de nuevo la fórmula cuasi litúrgica: "Todas estas son palabras del Almirante",

Pero, además de la cita en estilo directo, encontramos aquí una interpretación argumentativa que retoma en estilo indirecto las mismas frases de Colón, desvelándonos el propósito de Las Casas: mostrar que los pobladores de las Indias eran aquellos "Seres" que Plinio, Ponponio Mela, Estrabón, Virgilio, San Isidoro, Boecio y otros autores llaman "santísimos y felicísimos". He aquí el resumen que, consecuentemente con este propósito, precede a la cita literal en estilo directo:

El Almirante, viéndolos tan buenos y simples, y que en cuanto podían eran tan liberalmente hospitales, y con esto en gran manera pacíficos, dióles a muchos cuentas de vidrio y cascabeles, y a algunos bonetes colorados y otras cosas, con que ellos quedaban muy contentos y ricos ${ }^{15}$.

Contra las acusaciones de agresividad, insiste Las Casas en el pacifismo de estas gentes, que no sienten vergüenza de su desnudez, de modo que, según Las Casas, "parecía no haberse perdido o haberse restituido el estado de inocencia'. Contra Sepúlveda, que sobre la base de textos de Aristóteles consideraba a los indios seres inferiores ("sin alma"), obligados por ello a servir al hombre (hispano), Las Casas hace resaltar sus cualidades humanas. Más aún, parece que el texto todo se propone probar que están dotados de las tres facultades que distinguen al hombre del animal en la escolástica aristotélico-tomista: memoria, entendimiento y voluntad. Y de buena disposición para hacerse cristianos, ya que "ninguna secta tenían". Esta última consideración es capital, pues se tratará de evangelizar, más que de destruir infieles, con lo que la presencia española quedaba legitimada para Las Casas como cumplimiento de la misión evangelizadora confiada a los españoles por Roma. Sepúlveda, por el contrario, no parecía haber comprendido del todo que si los indios no eran seres humanos, tampoco eran sujetos aptos para recibir el bautismo. El "título de dominio" sobre aquellas tierras, basado en la "misión evangelizadora" de los españoles, desaparecía así en aras de una mayor p. 204

15 Ed. de Agustín Millares Carlo, 3 vols., F.C.E., México, 1981, vol. 1, 
libertad para someter a sus pobladores a la esclavitud ${ }^{16}$. En fin, Las Casas utiliza este texto como argumento de autoridad. Para ello, lo identifica (definiendo la pragmática de su enunciación) como informe de Colón dirigido a los reyes. Este importante dato sobre el destinatario interno del informe de Colón, queda patente en el texto mismo: "Yo, placiendo a nuestro Señor, levaré de aquí al tiempo de mi partida seis a V.A. para que desprendan fablar". Pero, contrariamente a lo que ocurre en la fórmula de presentación del Diario, en que Las Casas se limita a decir que se trata de "palabras formales del Almirante", la presentación del texto de Colón en la Historia de las Indias reza así:

el cual [el Almirante], en el libro desta su primera navegación, que escribió para los Reyes Católicos, dice de aquesta manera ${ }^{17}$.

La circunstancia de su enunciación convierte para Las Casas el texto citado en un documento fidedigno sobre cuya autoridad puede basar su tesis acerca de la condición natural del indio (i.e., para Las Casas, antes de que fuese corrompido por los españoles). Pero también podemos deducir del circuito comunicativo en que surge tal texto, que sus enunciados constituyen un sintoma de la mentalidad colectiva dominante en aquella España. Pues toda argumentación se organiza en función del destinatario de la misma, con lo que dice más acerca de su receptor que acerca de su emisor. De ahí que, en una lectura sintomática de este texto, atribuyamos los datos obtenidos al imaginario colectivo hispano, no al individuo Cristobal Colón (ni a su nación de origen).

Hernando Colón usa un tanto libremente estos textos en su Historia de Almirante. En el capítulo XXIII, "Cómo el Almirante salió a tierra y tomó posesión de aquélla en nombre de los Reyes Católicos", resume así la secuencia del texto de Colón en que se describe la condición del indio:

Asistieron a esta fiesta y alegría muchos indios, y viendo el Almirante que eran gente mansa, tranquila y de gran sencillez, les dio algunos bonetes rojos y cuentas de vidrio, las que se ponían al cue-

16 Véase sobre este punto el curioso estudio de Ramón Menéndez Pidal, "Vitoria y Las Casas", en El P. Las Casas y Vitoria con otros temas de los siglos xvi y xvii, Espasa-Calpe, Madrid, 1958. Me referiré al mismo en las páginas que siguen.

${ }^{17}$ Loc. cit. en n. 15. 
llo, y otras cosas de poco valor, que fueron más estimadas por ellos que si fueran piedras de mucho precio ${ }^{18}$.

La transformación del sintagma fijo "piedras preciosas", que parece condensar el valor de uso, en "piedras de (mucho) precio", condensado del valor de cambio, muestra un desplazamiento en la lectura del texto en cuestión. La escena idílica del acto de posesión de la isla utópica, cuyo relato parecía dominado por el viejo tópico del locus amoenus, se ha convertido ahora en una escena de mercado, de intercambio de bienes, considerados además desde el punto de vista de su valor de cambio.

Un análisis de este texto desde la perspectiva de la presencia en el mismo (por contaminación) de un discurso económico, confirma la lectura del Diario de su padre que parece sugerir aquí Hernando Colón, lectura que ha sido de nuevo puesta en circulación por Beatriz Pastor en su libro Discurso narrativo de la conquista de América, si bien desde una perspectiva diferente de la nuestra.

Beatriz Pastor destaca en su interesante estudio, junto a un "modelo literario" que, apoyado principalmente en Ailly, Aeneas Sylvio, Marco Polo y Plinio, guía la ficcionalización de la realidad por parte de Colón, otro "proceso de deformación profunda", " "El origen de este último - dice la autora - no es literario, sino económico, y su finalidad histórica es la propuesta, velada primero y después cada vez más explícita, de instrumentalización de la realidad del Nuevo Mundo con fines estrictamente comerciales'". Dentro de este marco interpreta Beatriz Pastor la caracterización del ingígena en el Diario de Colón:

Los tres primeros rasgos de caracterización de los indígenas según el código 1 -desnudez, pobreza y falta de armas - los definían como salvajes y siervos. El cuarto rasgo - la generosidad- los califica como bestias, por su incapacidad de comerciar de acuerdo con las leyes de intercambio del mundo occidental ${ }^{19}$.

Desde nuestra perspectiva de análisis discursivo creo descubrir en este texto, ya desde las primeras palabras del Almirante en torno a las gentes de aquella isla, la mercantilización (con toda evidencia, inconsciente) de sus seres y haberes. Pues el eje principal del relato lo ocupa la narración del intercambio de bienes y

${ }^{18}$ P. 112 en la ed. citada en la n. 12.

19 Beatriz Pastor, Discurso narrativo de la conquista de América, Casa de las Américas, La Habana, 1983, pp. 82 y 96-97. 
de (posibles) servicios que establece con ellos. Y en la estimativa de tales bienes, tal como la expresan los numerosos adjetivos del texto, se insiste más en el valor de cambio que en el valor de uso, comparándose (con criterios de rentabilidad) lo dado con lo recibido.

Comencemos por fijar nuestra atención ante todo en la organización morfosintáctica de las secuencias narrativas en las palabras que con tanta insistencia atribuye el P. Bartolomé de las Casas al Almirante. La alternancia de formas verbales correspondientes a lo que Harald Weinrich llama "mundo narrado" con las correspondientes al "mundo comentado" 20 , nos hará ver inmediatamente que en una primera secuencia del texto predominan verbos de acción en pretérito -en primera persona de singular (Colón) o en tercera persona de plural (la gente de la isla)-, mientras que en una segunda secuencia predominan verbos (de estado o no) en imperfecto o en presente. Finalmente, en una tercera secuencia encontramos modelizaciones del tipo "creo" o "deben ser", y verbos en condicional ("creo que ligeramente se harían cristianos") o en futuro, anunciando los propósitos del Almirante ("levaré de aquí al tiempo de mi partida seis a V.A. para que desprendan fablar").

La primera secuencia, con predominio de verbos de acción en pretérito, comprende una serie de frases finales, unas explícitas (" porque nos tuviesen mucha amistad"), otras implícitas en una copulativa que une la acción con el resultado intencional de la misma ("les di [...] con que hobieron mucho placer, y quedaron tanto nuestros que era maravilla"; "nos traían [ . . . ] y nos las trocaban"). Los verbos correspondientes a estas frases finales se distribuyen en forma que podríamos resumir en una combinatoria de dar y hacer (o de verbos equivalentes). La estructura de frase que observamos en esta primera secuencia del texto se corresponde pues a la letra con las formas contractuales, tal como las codifica ya el derecho romano, codificación que responde aún perfectamente a nuestra división actual del comercio según que se trate del intercambio de bienes, del intercambio de servicios o de un intercambio mixto:

$\begin{array}{lll}\text { do } & \text { ut } & \text { des } \\ \text { do } & \text { ut } & \text { facias } \\ \text { facio } & \text { ut } & \text { facias } \\ \text { facio } & \text { ut } & \text { des }\end{array}$

${ }^{20}$ Cf. Harald Weinrich, Tempus. Besprochene und erzählte Welt, Kohlhammer Verlag, Stuttgart, 1971. 
Además, como ya hemos indicado, los adjetivos que califican a los objetos de ese continuo trueque no hacen otra cosa que comparar lo dado o hecho con el don o servicio recibido ("porque nos tuviesen mucha amistad [...], les di unos bonetes colorados y unas cuentas de vidrio [... ] y otras cosas muchas de poco valor" ; " nos traían papagayos y hilo de algodón en ovillos y azagayas, y otras cosas muchas y nos las trocaban por otras cosas que nos les dábamos, como cuentecillas de vidrio y cascabeles"').

Todas estas comparaciones llevan a una doble conclusión: la primera, implícita en la comparación misma por el desnivel que establece entre lo dado y lo recibido, es que se trata de un trueque rentable; la segunda, explícita en el texto incluso con cierta insistencia, es que el resultado final de todo este comercio consiste en la posesión de aquellas gentes ("y quedaron tanto nuestros que era maravilla"'). Más aún, se establece una equivalencia entre amistad, entrega y conversión ("porque nos tuviesen mucha amistad, porque conoscí que era gente que mejor se libraría y convertiría a nuestra Santa Fe con amor que no por fuerza"').

La transición a la segunda secuencia, sobre "La índole y costumbres de aquella gente" (título dado por Hernando Colón al capítulo XXIV de su Historia del Almirante, eco precisamente de la secuencia que comentamos), la realiza un resumen-recapitulación de la secuencia anterior ("En fin todo tomaban y daban de aquello que tenían de buena voluntad"). Sigue después la parte descriptiva, con uso frecuente de la figura habitual en el discurso sobre la Edad de Oro, la litote: "Ellos andaban todos desnudos [...] ninguno vide de más de treinta años [...] Ellos no traen armas ni las cognoscen [...] No tienen algún fierro'”. Por último, entrelazadas con las anteriores, cierran esta secuencia las observaciones propias de un europeo renacentista, en que lo mismo se constata la belleza física ("muy bien hechos, de muy fermosos cuerpos, y muy buenas caras [...] Ellos todos a una mano son de buena estatura de grandeza, y buenos gestos, bien hechos"') y el cultivo del cabello o los colores con que se adornan, que se expresa la extrañeza ante la desnudez femenina. En la tercera secuencia destaca un primer párrafo que parece constituir al mismo tiempo la conclusión de las secuencias anteriores y el elemento lógico-sintáctico que comunica al conjunto su coherencia textual. En ella, en todo caso, encontramos la explicación funcional de cuantas observaciones preceden acerca del comportamiento y de las cualidades del indígena: 
Ellos deben ser buenos servidores y de buen ingenio, que veo que muy presto dicen todo lo que les decía, y creo que ligeramente se harían cristianos, que me pareció que ninguna secta tenían.

He intentado mostrar en otro lugar ${ }^{21}$ el impacto que un discurso propio de la mentalidad económica (burguesa) ejerce sobre el discurso ideológico oficial, incluida la (neo)escolástica que informa el pensamiento político y religioso de la España imperial, precisamente en el momento en que se intenta restaurar la mentalidad medieval (ya obsoleta). Ni siquiera Don Quijote, a pesar de su idealismo a toda prueba, escapa al contagio de su discurso caballeresco por el discurso propio del cálculo económico (cada vez más hegemónico, aunque no haya llegado aún a constituirse en discurso oficial). Es posible que no haya habido en la aventura de América el quijotismo que quiso ver en ella la Generación del 98 al hacer "balance” (¿económico?) sobre la misma. Quizás haya obedecido este diagnóstico sencillamente a la coincidencia del momento de sus meditaciones tras la independencia americana ("desastre colonial"' la llamaron) con el centenario del Quijote. Habría que analizar muchos más textos de la época para dar una respuesta adecuada a esta cuestión. De momento me contentaré con remitir a un par de documentos en torno a la conquista de Granada y a la colonización de América. Al igual que en el texto de Colón, en estos proyectos de idealización de la "empresa" no se logra del todo ocultar esa presencia cada vez más patente de un discurso económico que corroe el discurso misionero de aquellos políticos de la "pureza de la fe" y "salud de las almas". Encuentro ambos textos precisamente en estudios sobre las relaciones entre Iglesia y Estado en España, que intentan probar, a partir exclusivamente del explícito textual, la dimensión "profundamente religiosa" de la política (tanto interior como exterior) de la España imperial. El primero de estos documentos, fechado en marzo de 1485 , se refiere a la lucha que los reyes Fernando e Isabel preparan contra el reino de Granada; el segundo, fechado en septiembre de 1632, se refiere a la evangelización de América. El primero de estos documentos es la respuesta que Fernando V de Aragón hace llegar al papa Inocencio VIII por medio de sus embajadores en Roma, Antonio Graddino y Francisco de Rojas, en réplica al deseo del Papa de retener para la Sede Apostólica un tercio del

${ }^{21}$ Cf. An'tonio Gómez-Moriana, "Pragmática del discurso y reciprocidad de perspectivas: los juramentos de Juan Haldudo (Quijote, I, 4) y de Don Juan', NRFH, 36 (1988), 1045-1067. 
dinero que se obtuviese por la bula de cruzada que acababa de decretar en pro de la contienda contra los árabes en Granada. Su argumentación: facio ut des, do ut des. Para obtener del Papa la totalidad de lo recaudado, evoca el Rey sus servicios y su generosidad. En efecto, tras hacer saber que en aquella lucha no buscaba ni poder ni riqueza, continúa el rey español en el citado documento:

Pero el deseo que tenemos al servicio de Dios e celo a su santa fe católica, nos face posponer todos los intereses y olvidar los trabajos e peligros continuos que por esta causa se nos recrescen. Y podiendo, non solamente guardar nuestros tesoros, mas aún haber otros muchos de los moros mesmos, que muy voluntariamente nos los darían por la paz, negamos los que se nos ofrescen y derramamos los nuestros, solamente esperando que la santa fe católica sea acrescentada y la Cristiandad se quite de un tan continuo peligro como tiene aquí a las puertas, si estos infieles del Reino de Granada no son arrancados y echados de España ${ }^{22}$.

El segundo documento fue redactado por una comisión nombrada por el rey Felipe IV para defender ante la Nunciatura Apostólica en Madrid el "derecho" de la Corona española a mantener ciertos privilegios (regalías) que Roma pretendía abolir. Evoca en su argumentación los gastos y servicios de la corona española a la Sede Apostólica en la defensa y dilatación de la fe; Roma debe honorarlos, manteniendo tales regalías (do ut facias, facio ut facias). Dice así el punto 38 del documento preparado por la mencionada comisión:

Pues esta Corona gasta sus tesoros y emplea todas sus fuerzas en defensa de la fe, y ha dilatado nuestra sagrada Religión por tantos reinos y provincias tan extendidas, trayendo la nación española otros nuevos mundos a la obediencia a la Sede Apostólica $[\ldots]^{23}$.

Se trata en realidad de una constante histórica que alcanza

22 Apud José Goñ gazTambide, op. cit., Apéndice 15, pp. 671-676 (cita de la p. 672); para otros documentos de este período, of. Tratados internacionales de los Reyes Católicos con algunos textos complementarios ordenados y traducidos por José López de Toro, Imprenta Góngora, Madrid, 1952 (Documentos Inéditos para la Historia de España, ts. 7 y 8). Veáse igualmente la rica documentación manejada por Antonio Rouco Varela, op. cit.

23 "Parecer de la Junta sobre abusos en Roma y Nunciatura", ed. por QuinTín AlDEA como anejo a su artículo "Iglesia y Estado en la España del siglo xvii", Miscelánea Comillas, 36 (1961), 143-354. 
hasta época muy reciente, sumiendo la historiografía española en una interpretación del pasado cada vez más delirante. Pues el delirio de la interpenetración interdiscursiva crece en la misma medida en que la mentalidad económica va ocupando un lugar cada vez más hegemónico en el mundo moderno, tan inevitable como combatido por la España oficial. Veamos - de nuevo, a título de muestra - un texto (¿confesional?) de Menéndez Pelayo, entresacado de su Historia de los heterodoxos españoles:

Yo bien entiendo que estas cosas harán sonreír de lástima a los políticos y hacendistas, que, viéndonos pobres, abatidos y humillados a finales del Siglo XVII, no encuentran palabras de bastante menosprecio para una nación que batallaba contra media Europa conjurada, y esto no por redondear su territorio ni por obtener una indemnización de guerra, sino por ideas de Teología [ . . ] la cosa más inútil del mundo. ¡Cuánto mejor nos hubiera estado tejer lienzo y dejar que Lutero entrara y saliera donde bien le pareciese! [...] Nunca, desde el tiempo de ludas Macabeo, hubo un pueblo que con tanta razón pudiera creerse el pueblo escogido para ser la espada y el brazo de Dios; y todo, hasta sus sueños de engrandecimiento y de monarquía universal, lo referían y subordinaban a este objeto supremo: fiat unum ovile et unus pastor ${ }^{24}$.

Marcelino Menéndez Pelayo es "sin duda", como lo ha señalado Emilia de Zuleta en la "Introducción" a su Historia de la crítica española contemporánea, "el fundador de la crítica española moderna, en cuanto fija los conceptos generales y determina los métodos" ${ }^{25}$. A este mérito de Menéndez Pelayo, reconocido en general por la historiografía de la crítica literaria en España ${ }^{26}$, hay que añadir otra dimensión menos evidente y quizás también menos gloriosa: él es también quien imprime a la crítica española contemporánea una marca ideológica aún no superada. De ahí probablemente su inevidencia. Hay en la obra de Emilia de Zuleta una alusión a esta dimensión, que intentaré explicar más amplia-

${ }^{24}$ Ed. de la $B A C$, vol. 2, p. 328.

${ }^{25}$ Emilia de Zuleta, Historia de la crítica española contemporánea, Gredos, Madrid, 1966, p. 11.

${ }^{26}$ Cf. Dámaso Alonso, Menéndez Pelayo, crítico literario, Madrid, 1956; Ar turo Cayuel.a, Menéndez Pelayo, orientador de la cultura española, Madrid, 1954; Manuel Muñoz Cortés, "El humanismo de Menéndez Pelayo desde la perspectiva de la filología moderna”, 'AUM, 15 (1956-1957), 493-519; ÁNGEL DFI Río, Historia de la literatura española, New York, 1963; Pedro SaInz Rodríguez, Menéndez Pelayo, historiador y crítico literario, Madrid, 1956. 
mente. En el capítulo que dedica a Menéndez Pelayo -evidentemente, el primero del libro-, al describir los "caracteres generales" de su obra, destaca la autora "el sentido de unidad" como la "nota más constante" en la misma. Este sentido de unidad, que lo es también de "totalidad", va más allá de su inconfundible estilo - "personal y propio" en palabras de Emilia de Zuleta-, para constituir un trasfondo "más íntimo" en el que Emilia de Zuleta destaca dos elementos que transcribo:

El primer elemento de unidad en la obra de Menéndez Pelayo está dado por su apetencia de determinar, por vía de la historia literaria, una dirección espiritual única en el pasado español [ . . ]; a su juicio, el eje fundamental de ese pasado es el cruce de dos elementos integrados: lo nacional español y lo tradicional católico. Lo nacional español se ha ido perfilando y definiendo por sobre las diferencias, por virtud del sello romano que da los fundamentos unitarios en todos los órdenes, pero primariamente, por medio de la lengua. Posteriormente, esa unidad nacional se habrá de afianzar en la unidad de la creencia y hallará su síntesis más cabal durante el Siglo de Oro [...].

Un segundo elemento de unidad lo constituye el sentido total con que encara el proceso literario y cultural, tanto en el tiempo como en el espacio.

Para Menéndez Pelayo el ámbito hispánico - y por ende su literatura - tiene una amplitud mucho mayor que la que suelen reconocerle otros críticos investigadores. Abarca, por lo tanto, todo lo que fue hispánico en algún momento; no sólo España, sino Portugal e Hispanoamérica. Este ensanchamiento del campo influye directamente en su concepción de la literatura española, que se extiende desde la literatura latina hasta la literatura portuguesa y catalana, las influencias semíticas y la literatura hispanoamericana ${ }^{27}$.

Ya desde la España romana, pues, y no sólo desde el proceso de unificación de los reinos cristianos (y exclusión de las otras lenguas y culturas de la España medieval) que consuman Fernando $\mathrm{V}$ de Aragón e Isabel I de Castilla, asistimos al proceso de formación de ese Estado-nación de "dirección espiritual única'. Mejor no se podía explicar el aislamiento cultural a que Inquisición y censura someten durante siglos a esa nación. Ni se podía tampoco preparar mejor el terreno para la definición del "espíritu nacional" que proclama, ya en nuestro tiempo, el fascismo español, que impone por la fuerza durante casi medio siglo

27 Emilia de Zuleta, op. cit., pp. 16-17. 
la dictadura franquista, y que - sin dictadura - sigue aún en vigor por la inercia característica de las ideologías.

A pesar de las diferencias que median entre maestro y discípulo, la obra historiográfica de Menéndez Pidal no está tan lejos como pudiera creerse de esta concepción de una misión histórica española. Emilia de Zuleta los distingue por sus posiciones acerca de España: "Maestro y discípulo - afirma- difieren, eso sí, en una concepción ideológica básica: en el caso del primero, la de una España única, fundada en una sola tradición católica; en el caso del segundo, la de las dos Españas, escindidas y, a menudo, antagónicas' 28 . Es evidente que, frente al genio universal que se propone como meta ya desde su juventud Menéndez Pelayo, y frente a su clericalismo, Menéndez Pidal se perfila como especialista (historiador y filólogo) y como liberal. Un análisis atento de sus textos nos hará descubrir sin embargo que, a pesar de ciertos cambios léxicos (por ejemplo, "cultura de occidente" sustituye a "cristianismo"), sus argumentos presuponen como aceptados los mismos postulados nacionalistas que encontramos en el maestro, si bien ahora reducidos - centrados exclusivamente en Castilla. Es sobre todo en Los españoles en la historia y en la literatura (1951) donde más claramente reduce Menéndez Pidal lo español a lo castellano. Estamos de nuevo ante una España surgida en lucha contra el infiel y consolidada en el cumplimiento de una misión civilizadora. Lo que pasa es que esta lucha coincide precisamente con la expansión de Castilla (aquella Castilla "del desdén y de la fuerza” que - según los conocidos versos de Antonio Machado en Campos de Castilla - "envuelta en sus andrajos/desprecia cuanto ignora”'). Su misión civilizadora se realiza precisamente en la conquista de América.

Analicemos, como ejemplo que ilustra esta actitud frente a la conquista de América, unas frases de Menéndez Pidal sobre el (andaluz) P. Las Casas, sacadas de su libro "de máxima madurez"' (Laín Entralgo) El P. Las Casas y Vitoria ${ }^{29}$. Al resumir en el primero de sus ensayos, "Vitoria y Las Casas", la actitud de ambos teólogos dominicos frente a la conquista y colonización de América, dice Menéndez Pidal:

Hemos expuesto lo que acerca de la acción de España en América pensaron dos insignes dominicos. De una parte el andaluz Las Casas, inteligencia limitada por un corazón ciegamente apasionado,

28 Ibid., p. 197.

${ }^{29}$ Cf. supra, n. 16. 
escritor incansable de miles y miles de pliegos, jactancioso, amigo de ruido, diligente en publicar su opinión en diversas obras impresas en Sevilla [... ] Por otra parte el castellano viejo Vitoria, modesto, silencioso, de quien los coetáneos lamentaban que, a pesar de sus prodigiosas cualidades intelectuales, fuese muy enemigo de escribir $^{30}$.

Antes ha ido comparando las dos actitudes frente a lo que, con Vitoria, llama "títulos legítimos de dominio" de España en América. Al explicar el primero de los ocho títulos que establece Vitoria, afirma Menéndez Pidal:

El primer título legítimo por el que los bárbaros pueden venir al dominio de los españoles, según Vitoria, es la universal sociedad humana y la natural comunicación de los hombres. Todas las naciones tienen por inhumano el recibir mal a los huéspedes y peregrinos cuando no hay alguna causa en contrario. El derecho de gentes, derivado del derecho natural, establece el libre comercio y comunicación de los pueblos, el ius peregrinandi et degendi, a no mediar algún perjuicio especial que lo estorbe, y los españoles tienen derecho a peregrinar en las Indias y permanecer allí ${ }^{31}$.

Es así como, según afirma poco antes, se pone de manifiesto que "Vitoria no piensa como Las Casas, en abstracto; piensa en la realidad histórica, así que al título de la evangelización antepone el título del comercio, despreciado y relegado por Las Casas"'32. Parecería desenmascararse aquí sin más el pretexto religioso que (ideológicamente) justifica la acción española en América. Refiriéndose después a "Otros títulos no religiosos", Menéndez Pidal evoca, sin embargo, la acción civilizadora de España, con lo que vemos que se trata más bien de encontrar un sustituto (igualmente ideológico) a la tan manoseada justificación en nombre de una misión religiosa:

Las Casas no veía aquellos caciques, o "reyes", según él suele llamarlos, sino como soberanos de un estado equiparable en todo al del Rey Católico; con absoluto simplismo igualaba las gentes indias a los pueblos civilizados, mientras Vitoria $[\ldots]^{33}$.

33 Ibid., p. 27. 
Pero es en el segundo de los ensayos reunidos en este libro, "Una norma anormal del Padre Las Casas"34, donde mejor se percibe la comunión ideológica entre maestro y discípulo, con todas las diferencias que puedan, por otro lado, separarlos. En un esfuerzo polémico supremo contra la llamada "leyenda negra", que enturbia el pasado español en América, descalifica simplemente a su primer promotor, Las Casas, declarándolo loco. He aquí la argumentación de Menéndez Pidal:

Toda exageración es un desprecio a la verdad, y la exageración enormizante, habitual, irreprimible, es un desprecio que reviste caracteres patológicos.

Las Casas, a la vez que usa las hipérboles cuantitativas monstruosas, llega a una exageración cualitativa extrema ${ }^{35}$.

Aunque la conclusión de este silogismo no quede explícita aquí, resulta claro que se basa en ella el calificativo de "perturbado ánimo"' que después cuelga Menéndez Pidal a Las Casas, al tiempo que legitima la misión religiosa y civilizadora de su adversario. Acerca de "Las Casas y Hernando de Soto" afirma Menéndez Pidal, en efecto, al final de este ensayo:

El odio medieval entre dos religiones revive pujante en el perturbado ánimo de Las Casas para recaer sobre Hernando de Soto, que muere encomendando a Dios su alma y su cargo de Adelantado en la Florida, recibido de Carlos V para propagar la fe y la cultura del Occidente en las salvajes tierras del Nuevo Mundo ${ }^{36}$.

El sintagma "propagar la fe y la cultura del Occidente", junto al tono religioso en que se formula la defensa de Hernando de Soto (contra Las Casas) y la legitimación de su misión ("cargo") en Indias (en cuanto "recibido de Carlos V'), contradicen - al menos, contaminan - la interpretación secularizada de la presencia de España en Indias que parecía proponer Menéndez Pidal en el primer texto citado. Por otra parte, tal sintagma contextualiza el adjetivo "salvajes" con que califica a las "tierras del Nuevo Mundo" (en realidad, por metonimia, a sus habitantes), al igual que los sustantivos "bárbaros" y "gentes indias" que opone a "españoles", como también "caciques" a "reyes" (y, en espe-

34 Pp. 49-64.

35 Ibid., p. 53.

36 Ibid., p. 64. 
cial, al "Rey Católico") e "inhumano" a "derecho de gentes". Todo un sistema binario de conceptos (y de valores) caracteriza así las oposiciones que Menéndez Pidal establece entre "el andaluz Las Casas" y "el castellano viejo Vitoria", al igual que entre indios y españoles, lo que muestra una visión dualista, maniquea, tanto acerca de la acción de España en América como acerca de sus actores, y también de sus críticos o intérpretes.

Antonio Gómez-Moriana

Université de Montréal 